\title{
Caracterização da Distribuição Espacial das Fezes por Bovinos em uma Pastagem de Brachiaria decumbens ${ }^{1}$
}

\section{Sérgio Pereira Braz ${ }^{2}$, Domicio do Nascimento Júnior ${ }^{3}$, Reinaldo Bertola Cantarutti ${ }^{4}$, Carlos Eugênio Martins ${ }^{5}$, Dilermando Miranda da Fonseca ${ }^{3}$, Rodrigo Amorim Barbosa ${ }^{6}$}

RESUMO - O experimento foi conduzido no campo Experimental de Coronel Pacheco pertencente à EMBRAPA Gado de Leite, na Zona da Mata de Minas Gerais, com o objetivo de avaliar a distribuição espacial das fezes depositadas por bovinos na pastagem. Foi demarcado um piquete de forma quadrada com $110 \mathrm{~m}$ de lado numa pastagem de Brachiaria decumbens, com boa disponibilidade de forragem e cobertura homogênea. A área foi dividida em bordadura (faixa de $5 \mathrm{~m}$ em toda periferia) e área útil de avaliação (região central com $1 \mathrm{ha}$ ), onde se estudou a distribuição e cobertura das placas de fezes pelos animais na pastagem. As placas de fezes produzidas pelos três animais que permaneceram na área por 10 semanas cobriram $0,81 \%$ da superfície da área experimental. Os dados obtidos permitiram constatar a existência de duas regiões distintas quanto à densidade de deposição das defecações, uma associada ao ato de pastejo quando parte das defecações foram distribuídas na maior parte da área da pastagem, porém com densidade de defecações inferior a outra região distinta que está associada aos atos de descanso e ruminação, a qual ocupa menor área da pastagem, porém apresenta maior densidade de defecações.

Palavras-chave: binomial negativa, Poisson, índice de Morisita

\section{Characterization of Bovine Feces Spatial Distribution in a Brachiaria decumbens Pasture}

ABSTRACT - The experiment was carried out at the experimental station of EMBRAPA/National Dairy Research, at Coronel Pacheco, in the Zona da Mata region of Minas Gerais, to evaluate the qualitative aspects of nutrient recycling through the feces of grazing bovines. A 110 square meter plot was located in a previous established pasture of Brachiaria decumbens. The feces patches produced by the three animals remained in the area per 10 weeks and covered $0.8 \%$ of the surface. It was possible to observe the existence of two distinct regions of feces deposition. One associated with the grazing act when part of the feces were distributed with a lower density as compared to the other distinct area associated with rumination and resting, occupying a smaller area.

Key Words: negative binomial, Poisson, Morisita index

\section{Introdução}

Durante o pastejo dos bovinos, os animais percorrem a pastagem de forma homogênea e intensa para coleta do alimento. No entanto, o ato de excreção diferencia-se tanto temporalmente como espacialmente do pastejo, podendo-se verificar que grande concentração de placas de fezes em locais restritos e isolados, o que favorece a translocação dos nutrientes disponíveis na forragem para áreas com pouca ou nenhuma importância para produção, sendo este fato de grande relevância no processo de reciclagem de nutrientes nos ecossistemas de pastagens.

Os fatores que afetam a distribuição das fezes podem ser divididos entre os relacionados com a quantidade e freqüência das fezes produzidas, como a taxa de lotação, o sistema de pastejo, o tipo de animal (idade, sexo, raça, espécie), o manejo (ordenha etc) e os relacionados às atitudes comportamentais inerentes dos animais em relação às características ambientais como a temperatura ou declividade do terreno e às características da pastagem como o posicionamento das aguadas, bebedouros e sombras, além da forma da pastagem (relação comprimento/largura), entre diversos outros fatores. Essa complexidade de fatores restringem a elaboração de modelos que possam ser validados para uma ampla gama de situações.

Vários trabalhos descrevem a distribuição das fezes dos animais em pastejo utilizando modelos matemáticos.

\footnotetext{
1 Parte da dissertação de mestrado do $1^{\circ}$ autor.

2 Mestre em Zootecnia/UFV. E.mail: braz@ufrrj.br

3 Professor do DZO. Bolsista do CNPq. E.mail: domicion@ufv.br; dfonseca@ufv.br

4 Professor do Departamento de Solos/UFV. E.mail: cantarutti@ufv.br

5 Pesquisador da EMBRAPA/Gado de Leite. E.mail: caeuma@cnpgl.embrapa.br

6 Doutorando em Zootecnia/UFV. E.mail: guga@vicosa.mail.ufv.br
} 
Petersen et al. (1956) testaram vários modelos para descrever a distribuição das fezes nas pastagens e concluíram que o modelo da Distribuição Binomial Negativa foi o que proporcionou melhor ajuste aos dados observados. Posteriormente, este modelo foi utilizado com sucesso por Donald \& Leslie (1969), Richards \& Wolton (1976) e Morton \& Baird (1990).

Outra forma de avaliação do grau de agregação das placas de fezes é a utilização de índices de dispersão. Krebbs (1999) propôs além do tradicional índice de dispersão baseado na estimativa do parâmetro k do modelo da Distribuição Binomial Negativa, utilizados por muitos autores, a utilização do Índice de Morisita Padronizado, que se mostra mais apropriado para a caracterização de modelos de distribuição agregados uma vez que supre algumas deficiências características de outros índices.

O objetivo deste trabalho foi caracterizar a superfície coberta e a distribuição espacial das placas de fezes depositadas por bovinos em uma pastagem de Brachiaria decumbens, característica da região da Zona da Mata de Minas Gerais, pela utilização de modelos matemáticos.

\section{Material e Métodos}

O experimento foi conduzido no Campo Experimental de Coronel Pacheco pertencente à EMBRAPA Gado de Leite em Coronel Pacheco, na Zona da Mata de Minas Gerais (Lat. 210 35" S, Long. 430 15" W, Hp 0435,0 m), na mesma área e período em que Braz et al. (2002) conduziram ensaio relacionado, e a metodologia utilizada encontra-se ali descrita.

A partir dos registros das distribuições das placas em cada um dos 100 quadrados, foram calculadas estimativas dos parâmetros estatísticos como: $\sigma^{2}, \bar{x}$, $\Sigma \mathrm{X}_{\mathrm{i}}, \Sigma \mathrm{X}_{\mathrm{i}}^{2}$, com base no registro de cada uma das 10 semanas isoladamente, e dos totais acumulados durante as 10 semanas. Foram, então, calculadas as estimativas dos Índices de Dispersão, ajustados e avaliados o grau de aderência das freqüências observadas aos modelos de distribuição discreta de Poisson e Binomial Negativa, além do cálculo do expoente K da Distribuição Binomial Negativa e do Índice de Morisita Padronizado, também utilizados para caracterizar a distribuição das placas.

Na Figura 1, estão representados os modelos de distribuição espacial aleatório, agregado e o uniforme, utilizados na caracterização da distribuição das placas de fezes, seguindo adaptação de Krebs (1999).

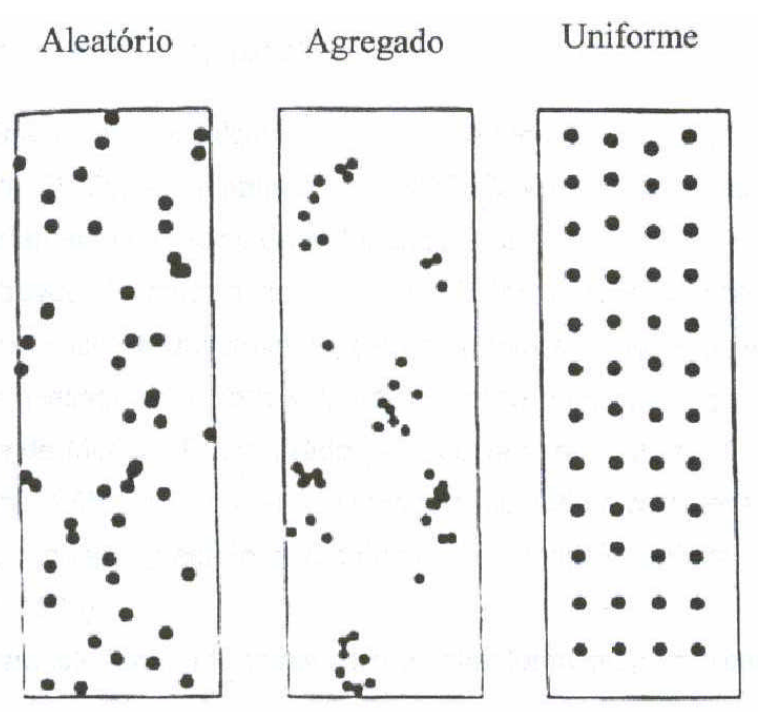

Figura 1 - Representação dos modelos de distribuição espacial aleatório, agregado e uniforme (adaptado de Krebs, 1999).

Figure 1 - Schematic representation of alleatory, aggregated and uniform distribution models (adapted from Krebs, 1999).

Finalmente, foi calculado o Índice de Morisita Padronizado proposto por Smith-Gill (1975) e adaptado por Krebs (1999), para caracterizar mais apropriadamente o modelo de distribuição.

Através do cálculo do Índice de Dispersão de Morisita $\left(\mathrm{I}_{\mathrm{d}}\right)$ (Morisita, 1972, citado por Krebs, 1999), do Índice de Uniformidade $\left(\mathrm{M}_{\mathrm{u}}\right)$ e do Índice de Agregação $\left(M_{c}\right)$, e posterior avaliação dos seus valores, foi obtida a fórmula específica de cálculo do Índice de Morisita Padronizado $\left(\mathrm{I}_{\mathrm{p}}\right)$, que varia de $-1,0$ $\mathrm{a}+1,0$, com limite de confiança de $95 \% \mathrm{a}+0,5$ e $-0,5$. O modelo aleatório é caracterizado por I $\mathrm{p}$ igual a zero, o modelo agregado acima de zero e o modelo uniforme abaixo de zero (Krebs, 1999).

\section{Resultados e Discussão}

Não se verificou variação estatisticamente significativa quanto à superfície coberta pelas placas de fezes, em função do tempo, sendo observado que a média da superfície coberta por cada placa de fezes excretada na área útil de avaliação foi de $0,0474 \mathrm{~m}^{2}$ (Figura 2).

Com base nos dados obtidos por Braz et al. (2002), pode-se confirmar o proposto por Corsi \& Martha Jr. (1997), os quais afirmam que os sistemas de produção com base em pastejo são praticamente auto sustentáveis, exigindo baixas quantidades de 


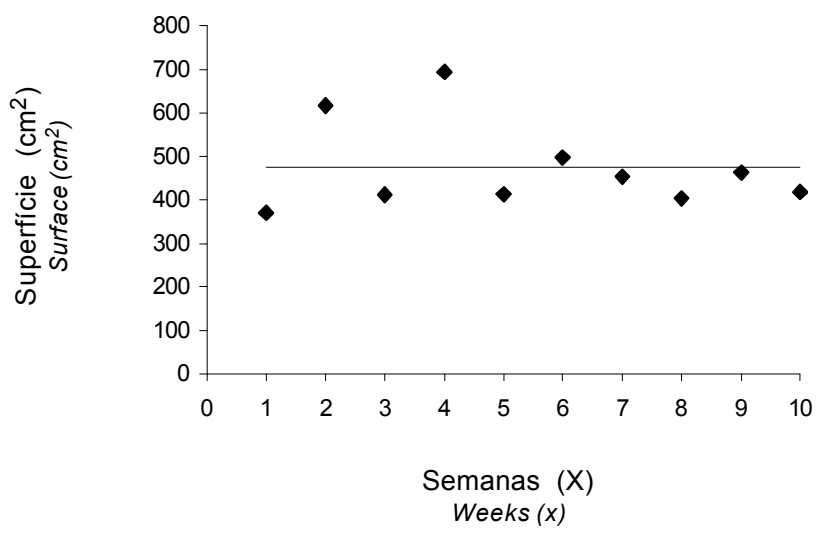

Figura 2 - Superfície coberta por placa de fezes, em $\mathrm{cm}^{2}$, na pastagem de $B$. decumbens, em função das semanas de amostragem.

Figure 2 - Surface covered by feces patches $\left(\mathrm{cm}^{2}\right)$, in a $B$. decumbens pasture as a function of sampling weeks.

insumos (fertilizantes e corretivos) para repor as perdas exportadas no produto animal, e que a continuidade da produtividade em tais sistemas parece ter condições de se manter em equilíbrio por um longo período de tempo, antes que seja necessária a reposição de nutrientes. Esses autores afirmam, porém, que os animais interferem significativamente alterando a distribuição e eficiência no aproveitamento dos nutrientes reciclados.

Desta maneira, a cobertura da pastagem pelas placas de fezes, determinada pela área de cada placa de fezes, bem como pela distribuição destas placas e em outro estádio, a liberação e disponibilização dos nutrientes destas placas para as plantas são pontos de estrangulamento que podem indicar a falta de sustentabilidade do ecossistema de pastagem cultivada.

Haynes \& Willians (1993), compilando dados de diversos autores, consideraram que a superfície coberta por uma simples defecação pode variar de 0,05 a $0,09 \mathrm{~m}^{2}$. During \& Weeda (1973), trabalhando com novilhas leiteiras, verificaram que a média da superfície coberta pelas placas de fezes foi de $0,05 \mathrm{~m}^{2}$, próxima à verificada neste estudo.

Considerando a freqüência média de defecações como 9,84 placas/animal/dia e a superfície coberta por uma placa de fezes como $0,0474 \mathrm{~m}^{2}$, pode-se estimar que a superfície coberta pelas placas de fezes de cada animal diariamente foi de $0,47 \mathrm{~m}^{2}$. Considerando ainda os 70 dias de duração do experimento, a presença dos três animais e a área total do piquete de $12100 \mathrm{~m} 2$, verificou-se que, durante este tempo, próximo de $0,81 \%$ da superfície da pastagem foi coberta pelas placas de fezes.

Marsh \& Campling (1970), compilando dados de diversos autores, estimaram que a superfície coberta pelas fezes de um bovino em um dia pode variar entre 0,45 e $1,1 \mathrm{~m}^{2}$, concluindo que a superfície coberta durante 180 dias de pastejo com lotação de um bovino por hectare representou cerca de 0,8 a 2,0\% da área da pastagem.

Pela avaliação do Índice de Dispersão (Krebs, 1999), verificou-se que a distribuição das placas de fezes dentro da área útil também não se deu de forma homogênea, assim, observou-se que em todos os grupos de registros de contagem das placas na área útil de avaliação, obtidos nas dez semanas de avaliação individualmente, a distribuição se dava de modo agregado e, portanto, a Distribuição de Poisson não poderia ser ajustada aos dados, deste modo, optou-se pela tentativa do ajuste dos dados à Distribuição Binomial Negativa.

Quanto à distribuição das placas de fezes na pastagem, Barrow (1967) distinguiu dois tipos de heterogeneidade no retorno das excreções na pastagem. Heterogeneidade local ou de pequena escala, que ocorre devido à deposição aleatória em determinada área e heterogeneidade de larga escala, que resulta da tendência do rebanho ser atraído para certa área da pastagem, resultando na concentração das excreções nesta área.

Segundo Wilkinson \& Lowrey (1973), as diferenças no modo de distribuição das excreções entre bovinos e ovinos podem ser relacionadas com a relativa proporção do tempo gasto em pastejo versus as outras atividades restantes. Eles assumem que a excreção durante o pastejo contribui para o ciclo de nutrientes, entretanto, as excreções associadas às áreas de descanso, ruminação, entre outras atividades, são responsáveis pelas perdas no ciclo de nutrientes na pastagem.

Petersen et al. (1956) avaliaram diversas distribuições de probabilidade para modelagem da distribuição espacial das fezes e concluíram que a Distribuição Binomial Negativa foi a que melhor se ajustou a seus dados, do mesmo modo que Richards \& Wolton (1976) e Morton \& Baird (1990). Estes últimos autores observaram que a Distribuição Binomial Negativa não se ajustou apenas em um dos 45 grupos de dados reportados.

Na Figura 3, está representada a freqüência observada do número de quadrados, que receberam $0,1,2$, 
$3, \ldots$ placas de fezes em cada uma das semanas de avaliação. Paralelamente também estão representadas as freqüências esperadas pela estimativa da Distribuição Binomial Negativa, quando esta se ajustou aos dados pelo teste $\chi^{2}$, em nível de $5 \%$ de probabilidade.

Quando se aplicou o teste do Índice de Dispersão sobre a média dos registros da contagem de placas nas dez semanas de avaliação, foi observado que, nesta situação, o modelo de distribuição foi classificado como aleatório e, assim, poderia ser descrito pela distribuição de Poisson, entretanto, pelo teste $\chi^{2}$, em nível de significância de $5 \%$, foram verificadas diferenças entre os dados observados e os preditos pela distribuição de Poisson, e assim a não adequação desta distribuição aos dados. Isto pode ser atribuído ao fato demonstrado pelos registros das avaliações de cada uma das semanas individualmente, em que se observou que os animais mantinham, na maioria das vezes, locais próprios para ruminação e descanso (sobretudo noturno), inclusive dentro da área útil de avaliação, o que pode ter caracterizado o tipo agregado de distribuição, quando se consideraram as semanas isoladamente, entretanto, com o passar das semanas, estes locais foram alterados, quando apresentavam elevada concentração de placas, podendo-se observar, durante todo o período de avaliação, a formação de diversas regiões com elevada concentração de placas.

Assim, pode-se observar que na região próxima ao bebedouro e ao cocho de sal, que foram locados em um dos cantos inferiores do relevo, havia quadrados com registros de placas depositadas muito superiores àqueles registrados na área central, e pode-se constatar visualmente que isto era devido à manutenção da atividade de ruminação, durante o dia, nesta área. Da mesma forma, pode-se verificar que na região próxima aos cantos superiores e, posteriormente, em uma das linhas superiores do relevo foram os locais escolhidos para o ato de descanso noturno dos animais, os quais eram alterados, quando a concentração de placas de fezes era elevada, favorecendo, desta forma, a formação de diversos pontos de concentração de placas na parte superior do piquete.

Diante disso, quando se avaliou os registros das semanas individualmente observou-se a agregação em pontos restritos, no entanto, quando se avaliou a média dos registros nas dez semanas em cada quadrado, pode-se constatar pela conclusão do teste do Índice de Dispersão que o modelo de distribuição era aleatório, no entanto, quando se procurou ajustar a
Distribuição de Poisson, apropriada para o modelo de distribuição aleatório (Krebs, 1999), constatou-se pelo teste $\chi^{2}$, em nível de $5 \%$ de probabilidade que os dados observados não se ajustavam aos preditos pela distribuição.

A elevada concentração de placas de fezes nas regiões próximas ao bebedouro, cocho de sal, sombras e linhas das cercas é comentada por diversos autores, entretanto, a observação do ato de descanso é pouco discutida na literatura. Segundo Peterson \& Gerrish (1996), em condições quentes e úmidas, bovinos de corte tendem a manter áreas de descanso nas regiões mais elevadas disponíveis. Como normalmente estas regiões tendem a ser secas e apresentar maior ocorrência de brisas frias, podem atrair os animais pelo maior conforto proporcionado.

$\mathrm{Na}$ Tabela 1 estão apresentadas as estimativas da média, do número de placas depositadas em cada quadrado na área útil de avaliação, o desvio-padrão desta média, o somatório do número de placas depositadas a cada semana na área útil, e o Índice de Morisita Padronizado, tanto para os dados das semanas consideradas isoladamente como acumuladas. Está apresentado também o parâmetro K da Distribuição Binomial Negativa nos casos em que esta distribuição se ajustou aos dados.

Pode ser observado na Tabela 1 que o Índice de Morisita Padronizado variou de 0,50 a 0,51, tanto para os registros considerando as semanas de avaliação isoladas, como para as semanas acumuladas. Segundo Krebs (1999), pode-se concluir que, quando este índice é maior que 0,5 , o modelo de distribuição das placas se dá de forma agregada para um intervalo de confiança de $95 \%$.

Richards \& Wolton (1976) fazem inferências aos dados de Petersen et al. (1956), sugerindo que os valores obtidos por estes autores referentes ao parâmetro K da Distribuição Binomial Negativa variaram de 1,5 a 2,0, indicando o modelo agregado para a distribuição das placas de fezes na pastagem. Os autores utilizaram este dado para comparar ensaios semelhantes, nos quais verificaram valores de $\mathrm{K}$ entre 2,7 e 17 , com média de 6,7, atribuindo seus resultados às altas densidades de lotação utilizadas, que proporcionaram a distribuição mais uniforme das placas de fezes sobre a pastagem. Esses dados diferiram dos obtidos por Petersen et al. (1956) que utilizaram taxas de lotação relativamente baixas.

Diante disso, pode-se explicar a aproximação dos valores de $\mathrm{K}$ deste estudo, que variaram entre $0,39 \mathrm{e}$ 
Primeira Semana

First week

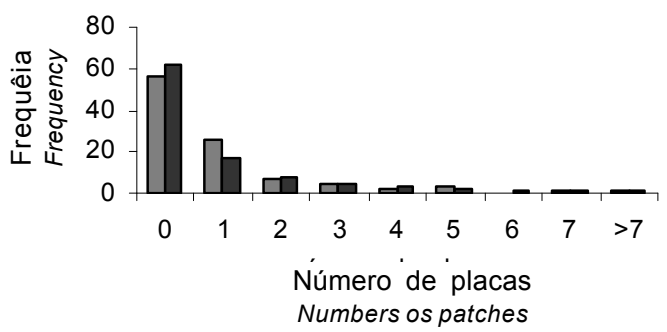

Terceira semana Third week

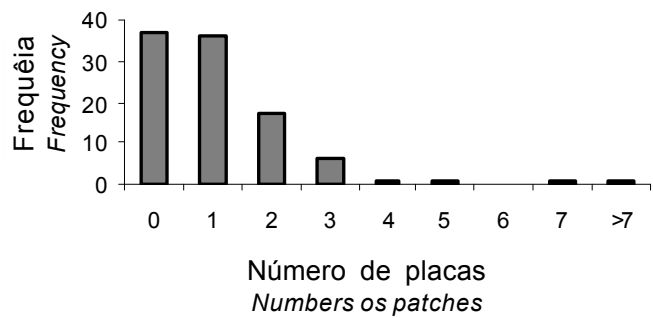

Quinta semana Fifth week
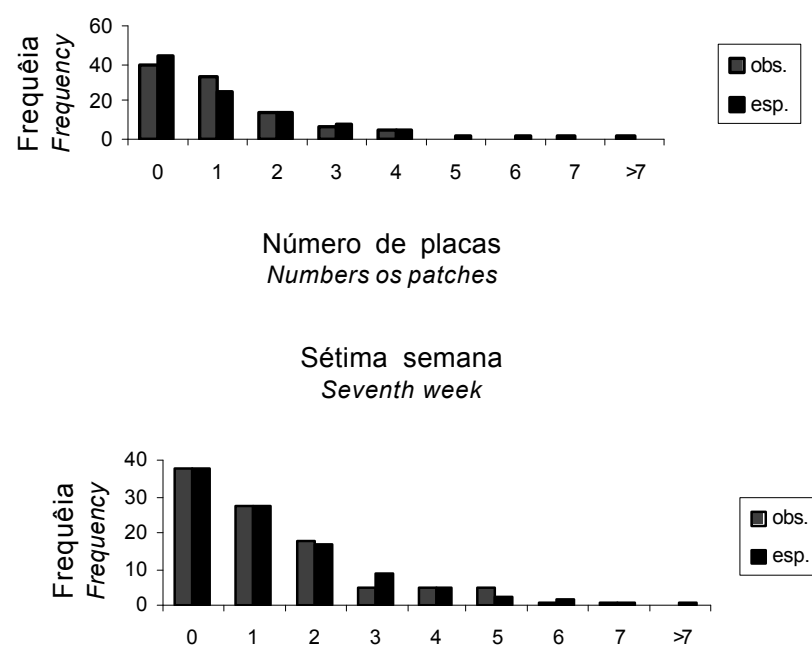

Número de placas

Numbers os patches

Nona semana Nine week

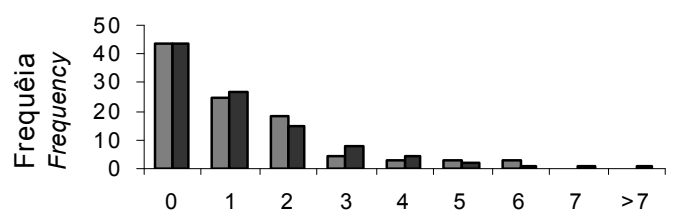

Número de placas Numbers os patches

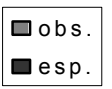

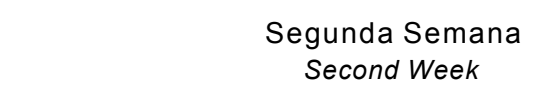

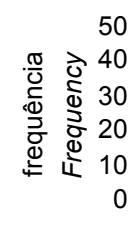

$\square$ obs.

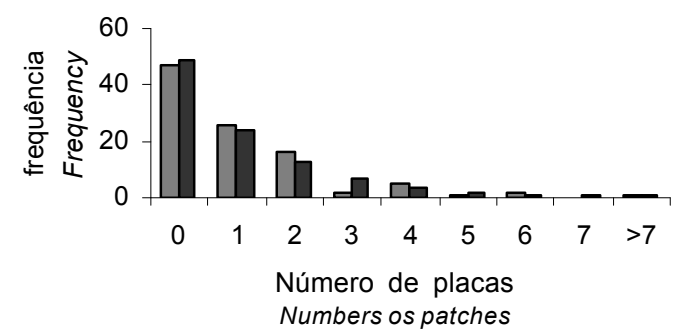

Sexta semana

Sixth week

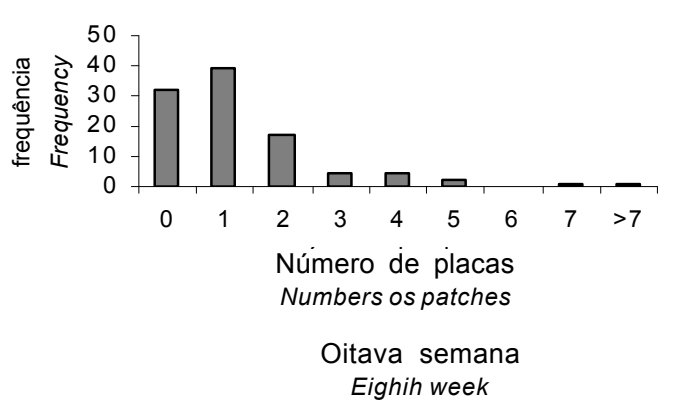

$\square$ obs. $\square$ obs.

esp.

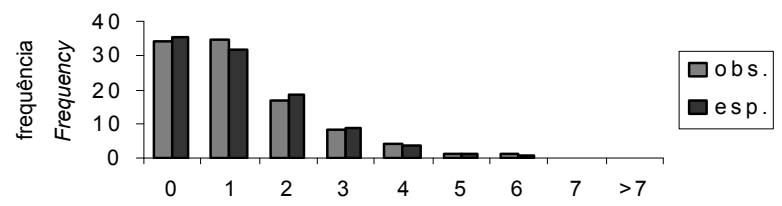

Número de placas

Numbers os patches

Décima semana Thent week

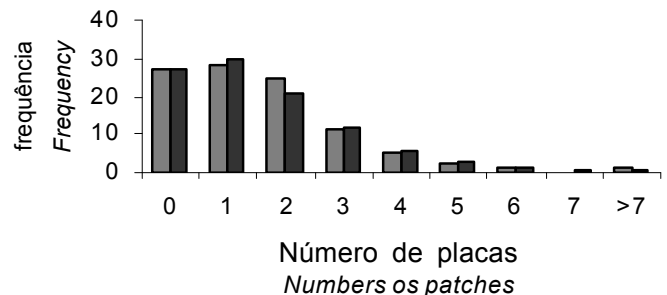

$\square$ obs

$\square$ esp.

Figura 3- Freqüências observada e esperada (quando ajustada ao modelo da Distribuição Binomial Negativa) de quadrados que receberam a deposição de $0,1,2, \ldots$ placas de fezes por quadrado, durante as 10 semanas de avaliação.

Figure 3 - Expected and observed frequencies (when adjusted to the negative binomial distribution model) of squares that received a deposition of 0.1. 2 ... feces patches per square, during the 10 evaluation weeks.

R. Bras. Zootec., v.32, n.4, p.787-794, 2003 
Tabela 1 - Estimativas das médias, do número de placas de fezes depositadas por quadrado na área útil, do desviopadrão da média, do somatório de placas depositadas e do Índice de Morisita Padronizado, considerando as semanas isoladamente e acumuladas, e estimativa do parâmetro $\mathrm{K}$ da Distribuição Binomial Negativa para os casos em que ocorreu o ajuste

Table 1 - Mean estimates, feces patches number deposited in each square of the sampling area, mean standard deviation, the total number of patches deposited and the standard Morisita index, considering weeks isolates and accumulated, and estimate of the $K$ parameter of the negative binomial distribution whenever adjustment occurred

\begin{tabular}{|c|c|c|c|c|c|c|c|c|c|}
\hline \multicolumn{2}{|c|}{$\begin{array}{l}\text { Semanas } \\
\text { Weeks }\end{array}$} & \multicolumn{3}{|c|}{$\begin{array}{l}\text { Semanas isoladas } \\
\text { Isolated weeks }\end{array}$} & \multirow[b]{2}{*}{$\begin{array}{l}\text { Parâmetro } \mathrm{K} \\
\text { K Parameter }\end{array}$} & \multirow[b]{2}{*}{$\begin{array}{l}\text { Média } \\
\text { Média }\end{array}$} & \multicolumn{3}{|c|}{$\begin{array}{l}\text { Semanas acumuladas } \\
\text { Accumalated weeks }\end{array}$} \\
\hline & $\begin{array}{l}\text { Média } \\
\text { Mean }\end{array}$ & $\Sigma \times$ & $\Sigma^{2}(\times)$ & $\begin{array}{l}\text { Índice de morisita } \\
\text { Morisita index }\end{array}$ & & & $\Sigma x$ & $\Sigma^{2}(\times)$ & $\begin{array}{c}\text { Índice de morisita } \\
\text { Morisita index }\end{array}$ \\
\hline 1 & 0,95 & 95 & 3,28 & 0,51 & 0,39 & - & - & - & - \\
\hline 2 & 0,84 & 84 & 1,43 & 0,50 & - & 1,79 & 179 & 7,32 & 0,51 \\
\hline 3 & 1,17 & 117 & 2,83 & 0,50 & - & 2,96 & 296 & 16,54 & 0,51 \\
\hline 4 & 1,10 & 110 & 2,47 & 0,50 & 0,88 & 4,06 & 406 & 27,43 & 0,51 \\
\hline 5 & 1,20 & 120 & 2,48 & 0,50 & 1,12 & 5,26 & 526 & 41,28 & 0,51 \\
\hline 6 & 1,28 & 128 & 2,45 & 0,50 & - & 6,54 & 654 & 57,28 & 0,51 \\
\hline 7 & 1,36 & 136 & 2,51 & 0,50 & 1,60 & 7,90 & 790 & 72,55 & 0,51 \\
\hline 8 & 1,20 & 120 & 1,58 & 0,50 & 3,83 & 9,10 & 910 & 84,28 & 0,50 \\
\hline 9 & 1,18 & 118 & 2,27 & 0,50 & 1,28 & 10,28 & 1028 & 98,51 & 0,50 \\
\hline 10 & 1,55 & 155 & 2,19 & 0,50 & 3,76 & 11,83 & 1183 & 112,02 & 0,50 \\
\hline
\end{tabular}

3,76 (Tabela 1), aos de Petersen et al. (1956), que também utilizou baixa pressão de pastejo, ao contrário de Richards \& Wolton (1976), que utilizaram pressões de pastejo superiores.

Hirata et al. (1987), utilizando uma pastagem com $1755 \mathrm{~m} 2$ dividida em 195 quadrados de 3 X3 m, contando com área adjacente, onde locou o bebedouro e havia sombras de árvores, em sistema de pastejo rotativo, com período de ocupação de 48 horas e lotação variando entre 21 e 24 novilhas, verificaram que a média do número de placas de fezes por quadrado para um período de pastejo individual variou entre 2 e 3 placas, entretanto, verificaram elevado coeficiente de variação (entre 79,5 e 139,3). O parâmetro $\mathrm{K}$ foi menor (entre 0,7 e 4,6), quando se consideraram períodos individuais de pastejo em comparação aos períodos acumulados de pastejo, podendo-se observar que neste caso o parâmetro K aumentou para 7,7, quando se consideraram dois períodos de pastejo, e para 10,4, quando se avaliaram oito períodos de pastejo consecutivos.

Na Figura 4 verifica-se a variação da porcentagem das classes de quadrados que receberam as de placas de fezes com o passar das 10 semanas de avaliação.

Pode-se observar, na Figura 4, que com aumento do período de pastejo ocorreu queda acentuada da porcentagem da classe de quadrados que receberam entre 0 e 4 placas de fezes, sendo que, paralelamente, ocorreu o aumento da porcentagem da classe de quadrados que receberam entre 4 e 8 placas. Podese observar ainda que, ao final das 10 semanas de avaliação, quando esta classe iniciou o declínio, a porcentagem da classe de quadrados que receberam entre 8 e 12 placas tendeu a aumentar. Pode-se observar também que as classes que receberam maior número de placas por quadrado não sofreram

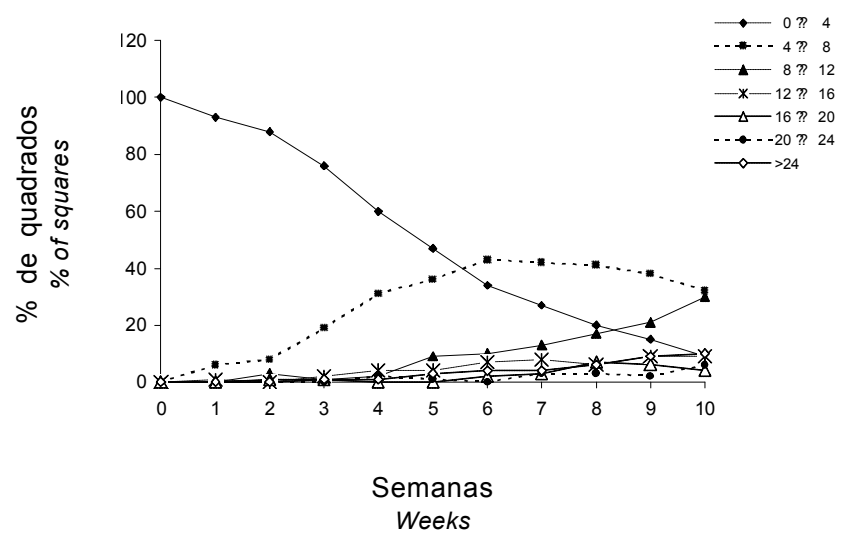

Figura 4 - Freqüência das classes de deposições de placas de fezes em pastagem de $B$. decumbens por quadrados como porcentagem do total.

Figure 4 - Class frequencies of patches feces deposition in a pasture of $B$. decumbens by square as $\%$ of the total. 
alterações expressivas.

Assim, foi verificada alteração dinâmica da porcentagem das classes de quadrados que receberam entre 0 e 4,4 e 8 e 8 e 12 placas por quadrado, de modo que, com o declínio da porcentagem de uma classe, a subseqüente demonstrou tendência para atingir o pico.

Também foi observada a maior quantidade de classes que apresentaram menor número de placas, sendo verificado, ao final das 10 semanas de avaliação, que as classes que receberam de 4 a 8 e de 8 a 12 placas perfaziam $70 \%$ dos quadrados totais, em contrapartida, as classes que receberam maior número de placas por quadrado representaram $30 \%$ dos quadrados.

Essa maior quantidade associada à alteração dinâmica da porcentagem das classes de quadrados pode caracterizar então uma região da pastagem representada por aproximadamente $70 \%$ da área que tende a ter uma freqüência de deposição de placas por quadrado aumentada de forma contínua e homogênea, embora em menor intensidade, que outra região distinta, caracterizada por representar próximo de $30 \%$ da área e por ter maior freqüência de deposição de placas de fezes.

Na Figura 5 está representado o croqui da área útil de avaliação e descrito o número de placas de fezes observadas em cada um dos 100 quadrados utilizados na avaliação.

Observa-se que os quadrados com altas densidades de placas (acima de 20 placas por quadrado), após as 10 semanas de avaliação, estão concentrados em sua totalidade nos cantos ou imediatamente ao lado deles e numa das linhas superiores da área de avaliação. Nestes locais, foi verificado visualmente no campo o predomínio da atividade de descanso ou ruminação, como já discutido anteriormente. Assim, apesar destas classes de quadrados serem representadas por menor número de quadrados em relação ao total, estes receberam grande parte das placas de fezes depositadas na pastagem.

Estes dados demonstram que a heterogeneidade na distribuição espacial das excreções na pastagem está relacionadas com as atividades diárias dos animais; assim, um número restrito de quadrados (16\%) que recebe grande porcentagem das deposições (43\%) durante um período de pastejo está relacionado à área de descanso e ruminação, enquanto a maioria dos quadrados que recebe proporcionalmente menor número de defecações está relacionado ao ato de pastejo.

\begin{tabular}{|c|c|c|c|c|c|c|c|c|c|c|}
\hline & & & & & & & & & & \\
\hline 47 & 20 & 8 & 14 & 11 & 9 & 6 & 10 & 38 & 67 & \\
\hline 11 & 3 & 4 & 9 & 28 & 21 & 26 & 22 & 29 & 6 & \\
\hline 13 & 15 & 9 & 12 & 10 & 6 & 8 & 7 & 8 & 15 & \\
\hline 7 & 4 & 8 & 1 & 3 & 9 & 11 & 6 & 13 & 13 & \\
\hline 6 & 11 & 6 & 6 & 10 & 10 & 4 & 10 & 2 & 5 & \\
\hline 10 & 8 & 2 & 7 & 7 & 5 & 3 & 5 & 5 & 15 & \\
\hline 7 & 5 & 6 & 2 & 10 & 6 & 4 & 4 & 4 & 11 & \\
\hline 10 & 8 & 7 & 9 & 4 & 10 & 9 & 15 & 6 & 3 & \\
\hline 20 & 18 & 10 & 11 & 0 & 5 & 7 & 19 & 22 & 23 & \\
\hline 32 & 31 & 18 & 11 & 6 & 4 & 8 & 16 & 36 & 42 & \\
\hline & & & & & & & & & & \\
\hline
\end{tabular}

Figura 5 - Distribuição do número de placas de fezes depositadas nos quadrados alocados na pastagem de $B$. decumbens nas 10 semanas de avaliação (estão sombreados os quadrados que receberam mais que 20 placas de fezes).

Figure 5 - Distribution of the feces patches number in the squares allocated in the $B$. decumbens pasture during the 10 weeks evaluation (shaded square are those that received more then 20 feces patches).

Este fato confirma o proposto por Barrow (1967), ou seja, a existência de dois tipos de heterogeneidade na distribuição das excreções na pastagem.

Gerrish et al. (1995), citados por Peterson \& Gerrish (1996), verificaram que a uma distância de 12 metros da fonte de água e a 15 metros da sombra das árvores foi marcante o aumento dos teores de nutrientes em relação a outras áreas da pastagem. Podese esperar, então, que estas distâncias são o limite de distinção entre as regiões de larga heterogeneidade e de heterogeneidade local proposta por Barrow (1967).

Comparando-se os dados obtidos neste estudo com os obtidos por Braz et al. (2002), que realizou ensaio relacionado na mesma área e determinou o número total de placas de fezes depositadas em toda área experimental, incluindo a área de bordadura, determinada neste estudo, com os resultados referentes ao número total de placas depositadas na área útil de avaliação, pode-se constatar que a diferença entre os números de placas depositadas que é representada pelas placas de fezes depositados na área de bordadura, que compreendia uma faixa de 5 metros em todo perímetro da área e recebeu um expressivo número de placas. 
O número total de placas depositadas em toda área não variou durante as semanas de avaliação, sendo observado um número médio 206,6 placas (Braz et al., 2002). Observou-se que a diferença entre o número de placas depositados na área total e o número de placas depositado na área útil apresentou variações importantes. Essa diferença nas semanas iniciais correspondeu a $69,79 \%$ das defecações, sendo então somente $30,21 \%$ correspondente das defecações verificadas na área útil do piquete. Com o passar das semanas, estas porcentagens alteraram-se, estabilizando-se nas últimas avaliações, com $66,04 \%$ das defecações ocorrendo na área útil da pastagem e 33,96\% das defecações correspondendo à diferença entre as duas áreas.

Considerando que a diferença entre as duas áreas (área de bordadura) corresponde a cerca de $12 \%$ da área total, a proporção de $34 \%$ de placas depositadas nesta área, frente aos $66 \%$ depositados na área útil, representa intensa heterogeneidade na distribuição das placas na pastagem.

Hirata et al. (1987) observaram que os bovinos permaneceram grande parte do tempo em área adjacente à pastagem, onde estava locado o bebedouro e tinha a presença de sombras de árvores. Constatouse que entre 11,4 e $29,5 \%$ das defecações ocorreram nesta área, que apresentava $60 \mathrm{~m}^{2}$ frente aos $1755 \mathrm{~m}^{2}$ do restante da área da pastagem.

\section{Conclusões}

A área coberta pelas placas de fezes cobre uma superfície muito pequena da área total da pastagem representando $0,81 \%$ da área total da pastagem durante o período experimental de 10 semanas.

A distribuição espacial das fezes na pastagem se dá de modo heterogêneo, apresentando duas regiões distintas que se diferenciam em função das atividades dos animais. Assim, associado ao ato de pastejo ocorre parte das defecações que são distribuídas na maior parte da área da pastagem, entretanto a densidade de defecações nesta região é inferior à região distinta que é associada aos atos de descanso e ruminação, que ocupa pequena área da pastagem, porém apresenta maior densidade de defecação.

A distribuição espacial das fezes na pastagem pode ser ajustada ao modelo de distribuição Binomial Negativa.

\section{Literatura Citada}

BARROW, N.J. Some aspects of the effects of grazing on the nutrition of pastures. Journal of Australian Institute of Agricultural Science, v.33, p.254-262, 1967.

BRAZ, S.P.; NASCIMENTO JR, D.; CANTARUTTI, R.B. et al. Aspectos quantitativos do processo de reciclagem de nutrientes pelas fezes de bovinos sob pastejo em pastagem de Brachiaria decumbens na Zona da Mata de Minas Gerais. Revista Brasileira de Zootecnia, v.31, n.2 (suplemento), p.858-865, 2002.

CORSI, M., MARTHA JR., G.B. Manutenção da fertilidade do solo em sistemas intensivos de pastejo rotacionado. In: In: SIMPÓSIO SOBRE MANEJO DA PASTAGEM, 14, Piracicaba, 1997. Anais... Piracicaba: Fundação de Estudos Agrários Luiz de Queiroz, 1997. p.161-192.

DONALD, A.D.; LESLIE, R.T. Population studies on the infective stage of some nematode parasites of sheep. II. The distribution of fecal deposits on fields grazed by sheep. Parasitology, v.59, p.141-157, 1969.

DURING, C.; WEEDA, W. C. Some effects of cattle dung on soli properties, pasture production, and nutriente uptake. New Zealand Journal of Agricultural Research, v.16, p.423430, 1973.

HAYNES, R. J.; WILLIAMS, P. H.Nutrient cycling and fertility in the grazed pasture ecosystem. Advanced Agronomy, v.49, p.119-199, 1993.

HIRATA, M.; SUGIMOTO, Y.; UENO, M. Distributions of dung pats and ungrazed areas in Bahiagrass (Paspalum notatum Flügge) pasture. Journal of Japanese Grassland Science, v.33, n.2, p.128-139, 1987.

KREBS, C.J. Ecological methodology. 2.ed. New York: Benjamin/Cummings, 1999. 620p.

MARSH, R.; CAMPLING, R.C. Fouling of pastures by dung. Herbage Abstracts, v.40, n.2, p.123-130, 1970.

MORTON, J.D.; BAIRD, D.B. Spatial distribution of dung patches under sheep grazing. New Zealand Journal of Agricultural Research, v.33, p.285-294, 1990.

PETERSEN, R.G.; LUCAS, H.L.; WOODHOUSE Jr., W.W. The distribution of excreta by freely grazing cattle and its effects on pasture fertility: I. Excretal distribution. Agronomy Journal, v.48, n.10, p.440-443, 1956.

PETERSON, P. R.; GERRISH, J.R. Grazing system and spatial distribution of nutrients in pastures: livestock management considerations. In: SYMPOSIUM NUTRIENTS CYCLING IN FORAGE SYSTEMS. Columbia, Missouri, 1996. Proceedings... Columbia, 1996. p.203-211.

RICHARDS, I.R.; WOLTON, K.M. The spatial distribution of excreta under intensive cattle grazing. Journal of the British Grassland Society, v.31, p.89-92, 1976.

WILKINSON, S.R., LOWREY, R.W. Cycling of mineral nutrients in pasture ecosystems. In: BUTLER, G.W.; BALLEY, R.W. (Eds.) Chemistry and biochemistry of herbage. New York: Academic Press, 1973. p.247-315.

Recebido em: 23/06/02 Aceito em: 07/12/02 